www.jmscr.igmpublication.org

Impact Factor (SJIF): 6.379

Index Copernicus Value: 79.54

ISSN (e)-2347-176x ISSN (p) 2455-0450

crossrefDOI: https://dx.doi.org/10.18535/jmscr/v6i10.168

Journal Of Medical Science And Clinical Research

IGM Publication

An Official Publication of IGM Publication

\title{
A Study on Clinical Effects of Grid Laser Photocoagulation in Diabetic Maculopathy
}

Authors

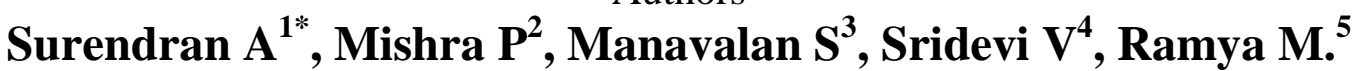

${ }^{* 1}$ Post Graduate, Department of Ophthalmology, Rajah Muthiah Medical College and Hospital, Annamalai University, Chidambaram

${ }^{2}$ Professor and Head of the Department, Department of Ophthalmology, Rajah Muthiah Medical College and Hospital, Annamalai University, Chidambaram

${ }^{3}$ Professor, Department of Ophthalmology, Rajah Muthiah Medical College and Hospital, Annamalai University, Chidambaram

${ }^{4}$ Reader, Department of Ophthalmology, Rajah Muthiah Medical College and Hospital, Annamalai University, Chidambaram

${ }^{5}$ Senior Resident, Department of Ophthalmology, Rajah Muthiah Medical College and Hospital, Annamalai University, Chidambaram

Abstract
Purpose: To assess the clinical effects of Grid laser photocoagulation in Diabetic macular edema.
Materials \& Methods: A total of 100 eyes of 50 patients with Diabetic Macular edema attending the
Department of Ophthalmology at Rajah Muthiah Medical College and Hospital, Chidambaram were the
target population of the study. Visual acuity for all patients was evaluated by Snellen's chart. Baseline
BCVA was $\geq 6 / 60$. Macular Grid laser photocoagulation was done for all the patients using $532 n m$ Diode
pumped solid state laser (DPSS) delivered by Slit lamp by modified ETDRS criteria. Patients were followed
up for a period of 3 months.
Results: Among the 50 patients 26 were Male (52\%) and 24 were Female (48\%). The mean age of the study
population was $55 y r s$. The mean BCVA BE of the patients; Pre \& Post laser showed no change (p $>0.5)$.
On 3 month follow up, $86 \%$ of eyes had a stable vision, $4 \%$ had improved vision of 1 line and $10 \%$ showed
decreased vision of 1 line in Snellen's chart.
Conclusion: Diabetic macular edema is a potentially sight threatening complication of people affected by
DM worldwide. Grid laser photocoagulation reduces the risk of moderate vision loss when treated early.
Keywords: Grid laser photocoagulation, Diabetic macular edema, clinically significant macular edema,
Diabetes mellitus.

\section{Background}

Diabetes mellitus (DM) is a global epidemic with significant morbidity. Diabetic retinopathy (DR) \& Diabetic macular edema (DME) are the specific microvascular complication of DM and affects 1 in 3 persons with DM. DR/DME remains a leading cause of vision loss in working adult populations ${ }^{1}$.

According to the WHO, 31.7 million people were affected by diabetes mellitus (DM) in India in the year 2000. This figure is estimated to rise to 79.4 million by 2030 , the largest number in any nation 
in the world. In 2014, The All India Ophthalmological society reported that approximately $21.7 \%$ of patients with diabetes had $\mathrm{DR}^{2}$. Macular oedema increases $3 \%$ in moderate NPDR, 38\% in severe NPDR and 71\% in PDR.

Epidemiological studies and clinical trials have shown that Diabetic macular edema results in irreversible loss of vision and is the major cause of visual morbidity in patients with Diabetes of adult onset. To date, the most effective means to reduce the risk of vision loss from DME includes focal/grid laser photocoagulation and intensive blood sugar control. In Early Treatment Diabetic Retinopathy study (ETDRS), Focal/Grid Laser photocoagulation of eyes with diabetic macular edema (DME) reduced the risk of moderate visual acuity loss (defined as a loss of 15 or more letters) by approximately $50 \%$. One of the major findings in the ETDRS study was that laser photocoagulation helped stabilised vision in majority of the patients ${ }^{3,4}$.

Clinically significant macular edema (CSME)/ Diabetic macular edema (DME) [ETDRS Classification]

- Thickening of the retina $<500$ microns from the center of the macula.

- Hard exudates with thickening of the adjacent retina located 500 microns from the center of the macula.

- A zone of retinal thickening, 1 disc area or larger in size located 1 disc diameter from the center of the macula.

ICO Guidelines

International council of Ophthalmology (ICO) in its guidelines for 2017 has further classified DME as follows ${ }^{1}$

\begin{tabular}{|l|l|}
\hline Diabetic macular edema & Findings observed on dilated Ophthalmoscopy \\
\hline No DME & No retinal thickening or hard exudates in the macula \\
\hline Non central-involved DME & $\begin{array}{l}\text { Retinal thickening in the macula that does not involve } \\
\text { the central subfield zone that is } 1 \mathrm{~mm} \text { in diameter }\end{array}$ \\
\hline Central-involved DME & $\begin{array}{l}\text { Retinal thickening in the macula that involves the } \\
\text { central subfield zone that is } 1 \mathrm{~mm} \text { in diameter }\end{array}$ \\
\hline
\end{tabular}

\section{Materials and Methods}

The aim of this study is to observe the effects of Grid laser photocoagulation in eyes with clinically significant macular edema.

In this Prospective clinical study 100 eyes of 50 patients attending the Department of Ophthalmology at Rajah Muthiah Medical College and Hospital, Chidambaram from October 2017 to September 2018 with Diabetic macular edema was included.

\section{Inclusion criteria}

- Patients with Non Proliferative Diabetic Retinopathy with Diabetic Macular edema

- Best corrected visual acuity $\geq 6 / 60$ using Snellen's chart.

Exclusion criteria: Patient with Diabetic Macular edema having
- Retinal thickening from epiretinal membranes or vitreomacular traction

- Had YAG capsulotomy within 2 months.

- Major ocular surgery including cataract surgery within the prior 6 months.

- Patients with Proliferative diabetic retinopathy.

Visual acuity for all patients were evaluated by Snellen's chart.

The patients were then examined under Slit lamp Biomicroscope to rule out anterior segment diseases that could alter visual outcome.

The posterior segment was examined with an Indirect Ophthalmoscope and 20D lens with a fully dilated pupil and were diagnosed according to the ETDRS classification for CSME/DME.

IOP was checked using TOPCON non-contact tonometer. 
Basic clinical investigations for assessing the current diabetic status of the patients were done.

Patients were then treated with IRIDEX OCULIGHT-GL DPSS Grid Laser photocoagulation delivered by Slit lamp using Volk Centralis, HPF magnifying contact lens under LA in the Department of Ophthalmology at Rajah Muthiah Medical College and Hospital after obtaining informed written consent.

Grid Laser photocoagulation was done in a single sitting for all study population on an outpatient basis.

Laser settings

- Duration- 100-200ms

- Spot size- 50 - 100 microns

- Power-150-300 mJ
- Intensity-mild to moderate

- 1 burn width apart, $500 \mu$ from centre of macula and $500 \mu$ from temporal margin of disc

Patients were followed up for a period of 3 months post treatment and VA recorded using Snellen's chart and corresponding ETDRS score was assigned for the purpose of statistical analysis.

\section{Statistical analysis}

All the data was entered into Microsoft Excel Sheet and statistical analysis was arrived by using IBM SPSS software version 22. All the data was presented as mean, standard deviation and percentage. Chi-square test was done to evaluate statistical significance. Wilcoxon signed ranks test was done to assess the outcome of the treatment.

\section{Results}

Table 1 Age-wise Distribution

\begin{tabular}{|l|c|c|}
\hline Age distribution & No of Patients & Percentage \\
\hline $30-40$ & 3 & 6.0 \\
\hline $41-50$ & 14 & 28.0 \\
\hline $51-60$ & 20 & 40.0 \\
\hline $61-70$ & 12 & 24.0 \\
\hline $71-80$ & 1 & 2.0 \\
\hline Total & 50 & 100.0 \\
\hline
\end{tabular}

Most of the patients in the study were in the age group of 51-60 yrs (40\%)

Table 2 Sex Distribution

\begin{tabular}{|l|c|c|}
\hline Sex & No of patients & Percentage \\
\hline Female & 24 & 48.0 \\
\hline Male & 26 & 52.0 \\
\hline Total & 50 & 100.0 \\
\hline
\end{tabular}

The study population had 26 Male patients (52\%) and 24 female patients (48\%).

Table 3 Duration of DM

\begin{tabular}{|l|c|c|}
\hline Duration of DM & No. of patients & Percentage \\
\hline$<5$ & 18 & 36 \\
\hline $6-10$ & 21 & 42 \\
\hline $11-15$ & 4 & 8 \\
\hline $16-20$ & 6 & 12 \\
\hline $21-25$ & 1 & 2 \\
\hline Total & 50 & 100 \\
\hline
\end{tabular}

In the present study the mean duration of DM was 6-10yrs in $21(42 \%)$ patients, followed by <5yrs in $18(36 \%)$; $16-20 \mathrm{yrs}$ in $6(12 \%) ; 11-15 \mathrm{yrs}$ in $4(8 \%)$ and $21-25 \mathrm{yrs}$ in $1(2 \%)$ 
Table 4 Comparison of Pre/Post Laser BCVA RE

\begin{tabular}{|l|c|c|c|c|}
\hline \multirow{2}{*}{ BCVA } & \multicolumn{2}{|c|}{ Prelaser } & \multicolumn{2}{c|}{ 3 month follow up } \\
\cline { 2 - 5 } & No of eyes & Percentage & No of eyes & Percentage \\
\hline $6 / 60$ & 2 & 4 & 3 & 6 \\
\hline $6 / 36$ & 13 & 26 & 13 & 26 \\
\hline $6 / 24$ & 8 & 16 & 7 & 14 \\
\hline $6 / 18$ & 8 & 16 & 8 & 16 \\
\hline $6 / 12$ & 8 & 16 & 9 & 18 \\
\hline $6 / 9$ & 9 & 18 & 9 & 18 \\
\hline $6 / 6$ & 2 & 4 & 1 & 2 \\
\hline Total & 50 & 100 & 50 & 100 \\
\hline
\end{tabular}

In the above table on comparison of BCVA RE Pre/Post laser indicates that majority of the eyes had a stable vision; 42/50 (84\%) post treatment.

Fig 1 Comparison of Pre/Post Laser BCVA RE

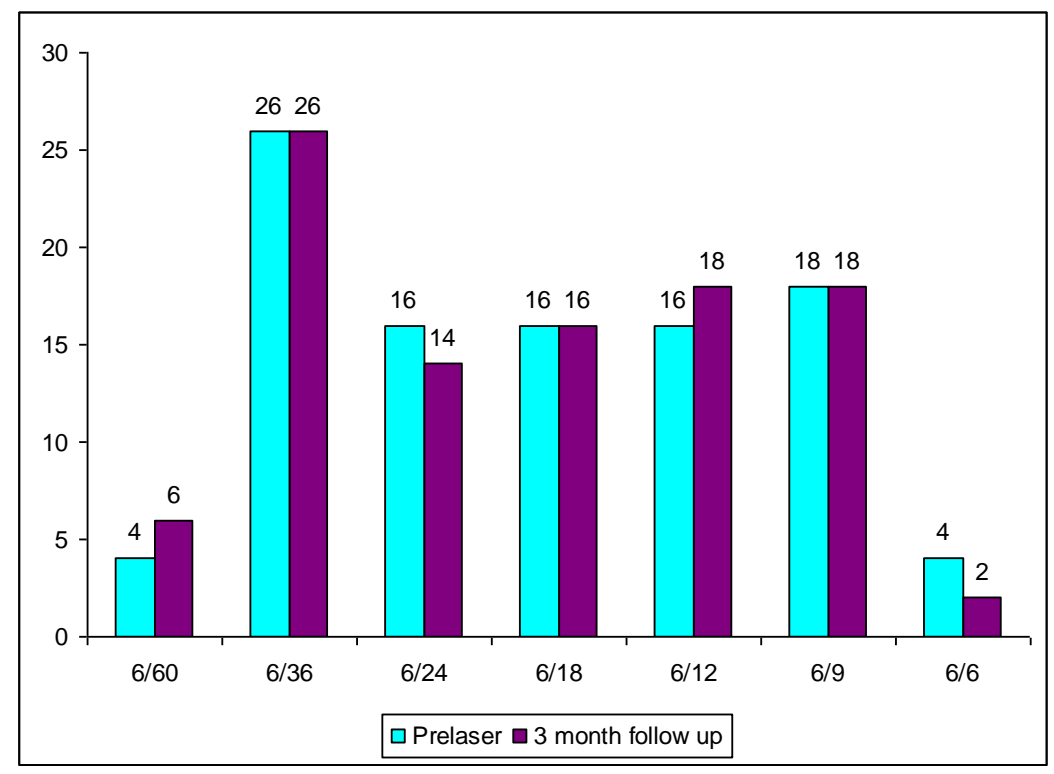

Table 5 Chi-Square test RE

\begin{tabular}{|l|c|c|c|c|}
\hline \multirow{2}{*}{ ETDRS Score } & \multirow{2}{*}{ Mean } & \multirow{2}{*}{ SD } & \multicolumn{2}{|c|}{ Paired sample test } \\
\cline { 5 - 5 } & & & 't'value & 'p'value \\
\hline RE Prelaser & 59.60 & 13.12 & \multirow{2}{*}{1.31} & .197 \\
\hline RE Postlaser & 58.90 & 13.14 & & \\
\hline
\end{tabular}

The mean ETDRS score of RE Prelaser was $59.60 \pm 13.12$ and Post laser was $58.90 \pm 13.14$. But the difference was insignificant ( $p>.05$ ) which implies that the vision remained stable post treatment.

Table 6 Wilcoxon Signed Ranks Test RE

\begin{tabular}{|l|c|}
\hline BCVA Pre/Post Laser RE & N \\
\hline Negative Ranks & 6 \\
\hline Positive Ranks & 2 \\
\hline Ties & 42 \\
\hline Total & 50 \\
\hline
\end{tabular}

In our study, on comparison of Pre \& Post laser BCVA of RE, 42 (84\%) eyes had stable vision post laser treatment, 2 (4\%) eyes showed improvement of vision and $6(12 \%)$ eyes showed worsening of vision. 
Table 7 Comparison of Pre/Post Laser BCVA LE

\begin{tabular}{|l|c|c|c|c|}
\hline \multirow{2}{*}{ BCVA } & \multicolumn{2}{|c|}{ Prelaser } & \multicolumn{2}{c|}{ 3 month follow up } \\
\cline { 2 - 5 } & No of eyes & Percentage & No of eyes & Percentage \\
\hline $6 / 60$ & 1 & 2 & 2 & 4 \\
\hline $6 / 36$ & 13 & 26 & 14 & 28 \\
\hline $6 / 24$ & 9 & 18 & 7 & 14 \\
\hline $6 / 18$ & 8 & 16 & 8 & 16 \\
\hline $6 / 12$ & 10 & 20 & 10 & 20 \\
\hline $6 / 9$ & 6 & 12 & 6 & 12 \\
\hline $6 / 6$ & 3 & 6 & 3 & 6 \\
\hline Total & 50 & 100 & 50 & 100 \\
\hline
\end{tabular}

The above table implies that on comparison of BCVA of LE Pre/Post laser treatment majority of eyes $44 / 50(88 \%)$ had a stable vision post treatment.

Fig 2 Comparison of Pre/Post laser BCVA LE

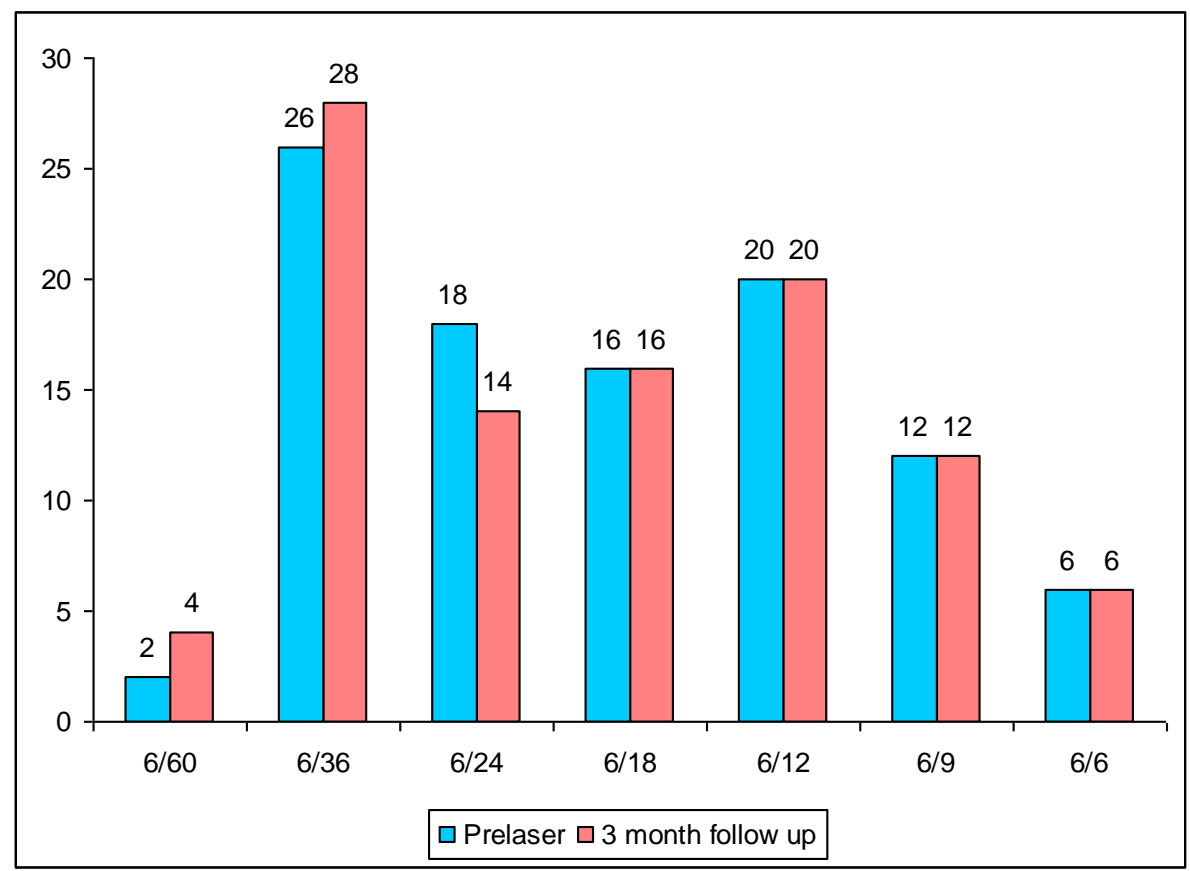

Table 8 Chi-Square test LE

\begin{tabular}{|l|c|c|c|c|}
\hline \multirow{2}{*}{ ETDRS Score } & \multirow{2}{*}{ Mean } & \multirow{2}{*}{ SD } & \multicolumn{2}{|c|}{ Paired sample test } \\
\cline { 5 - 5 } & & & 't'value & 'p'value \\
\hline RE Prelaser & 60.00 & 12.78 & \multirow{2}{*}{0.94} & 0.35 \\
\hline RE Postlaser & 59.60 & 13.09 & & \\
\hline
\end{tabular}

The mean ETDRS score of LE Prelaser was $60.00 \pm 12.78$ and Post laser was $59.60 \pm 13.09$. But the difference was insignificant ( $\mathrm{p}$ value $>.05$ ) which implies that the vision remained stable after laser treatment.

Table 9 Wilcoxon Signed Ranks Test LE

\begin{tabular}{|l|c|}
\hline BCVA PRE/POST Laser LE & N \\
\hline Negative Ranks & 4 \\
\hline Positive Ranks & 2 \\
\hline Ties & 44 \\
\hline Total & 50 \\
\hline
\end{tabular}


In our study, on comparison of Pre \& Post laser BCVA of LE, $44(88 \%)$ eyes had stable vision post laser treatment, $2(4 \%)$ eyes showed improvement of vision and $4(8 \%)$ eyes showed worsening of vision.

The mean age of the patients in the study was $55 \mathrm{yrs}$. Most of the patients in the study were in the age group of 51-60 yrs (40\%).

The study population had 26 Male patients (52\%) and 24 female patients (48\%).

The mean duration of DM in the patients included in our study was 6-10 yrs (42\%).

The mean ETDRS score RE was $59.60 \pm 13.14$ and LE was $60.00 \pm 12.78$ in the study population before laser treatment. On 3 month follow up, the mean ETDRS score RE was $58.90 \pm 13.14$ and LE was $59.60 \pm 13.09$. On comparison by Chi-Square test the data was clinically insignificant in both eyes $(p>0.5)$. The result indicates that most of the patients had a stable vision post laser treatment.

\section{Discussion}

On comparison of Pre/Post laser BCVA of the study population, a total $86 \%$ of eyes had stable vision following Grid laser treatment in our study as compared to $77 \%$ in McDonald, Schatz ${ }^{5}$ et al; $86 \%$ in Laursen ${ }^{6}$ et al; $77 \%$ in Lee, $\mathrm{Olk}^{7}$ et al; $88 \%$ in Akduman, $\mathrm{Olk}^{8}$ et al; $65 \%$ in Tewari ${ }^{9}$ et al; $76 \%$ in Shahid $\mathrm{MJ}^{10}$ et al;42\% in Masahiko $\mathrm{S}^{11}$ et al; $50 \%$ in Scott $\mathrm{U}^{12}$ et al.

A total of $4 \%$ of eyes had improved vision in our study which was lower as compared to $17 \%$ in McDonald, Schatz ${ }^{5}$ et al; $5 \%$ in Laursen $^{6}$ et al; $14 \%$ in Lee, $\mathrm{Olk}^{7}$ et al; $8 \%$ in Akduman, $\mathrm{Olk}^{8}$ et al; $20 \%$ in Tewari ${ }^{9}$ et al; $11 \%$ in Shahid $\mathrm{MJ}^{10}$ et al; $45 \%$ in Masahiko $\mathrm{S}^{11}$ et al; $18 \%$ in $\mathrm{Scott} \mathrm{U}^{12}$ et al.

A total of $10 \%$ eyes had worsening of vision in our study as compared to $6 \%$ in McDonald, Schatz ${ }^{5}$ et al; $9 \%$ in Laursen ${ }^{6}$ et al; $9 \%$ in Lee, $\mathrm{Olk}^{7}$ et al; $4 \%$ in Akduman, $\mathrm{Olk}^{8}$ et al; $15 \%$ in Tewari $^{9}$ et al; $13 \%$ in Shahid $\mathrm{MJ}^{10}$ et al; $11 \%$ in Masahiko $\mathrm{S}^{11}$ et al; $32 \%$ in Scott $\mathrm{U}^{12}$ et al.

Other parameters such as Central macular thickness (CMT) and macular perfusion could not be assessed due to non availability of FFA and OCT.

\section{Conclusion}

Diabetic macular edema is a potentially sight threatening complication of people affected by DM worldwide.

Early diagnosis by frequent screening and strict blood sugar control can prevent the visual morbidity associated with macular edema.

Laser photocoagulation is the gold standard procedure for Diabetic Macular edema. It is the benchmark of comparison for all the other newer treatment modalities for the past $30 \mathrm{yrs}$.

In recent changing times, it still holds importance in being the most cost effective treatment procedure for sight threatening complication of Diabetic retinopathy that is CSME as evidenced by our study.

\section{Bibliography}

1. International Council of Ophthalmology. Guidelines for Diabetic Eye Care, January 2017

2. Gadkari SS, Maskati QB, Nayak BK. Prevalence of diabetic retinopathy in India: The All India Ophthalmological Society Diabetic Retinopathy Eye Screening Study 2014. Indian J Ophthalmol 2016;64:38-44.

3. Early Treatment Diabetic Retinopathy Study Research Group. Photocoagulation for diabetic macular edema. Early Treatment Diabetic Retinopathy Study report number 1. Arch Ophthalmol 1985;103:1796-806.

4. Early Treatment Diabetic Retinopathy Study Research Group. Photocoagulation for diabetic macular edema: early treatment diabetic retinopathy study report number 4. Int. Ophthalmol. Clin. 27, 265272 (1987).

5. McDonald HR, Schatz H. Grid photocoagulation for diffuse macular edema. Retina 5(2), 65-72 (1985). 
6. Pugesgaard T, Laursen AB. Modified grid pattern treatment of diabetic perifoveal edema by orange dye laser photocoagulation. Acta Ophthalmol. Copenh. 66(3), 286-292 (1988).

7. Lee CM, Olk RJ. Modified grid laser photocoagulation for diffuse diabetic macular edema: long-term visual results. Ophthalmology 98, 1594-1602 (1991).

8. Akduman L, Olk RJ. Diode laser versus argon green modified grid photocoagulation for diffuse diabetic macular edema. Ophthalmology 1997; 104: 1433-1441.

9. Tewari HK, Gupta V, Kumar A, Verma L. Efficacy of diode laser for managing diabetic macular oedema. Acta Ophthalmol. Scand. 76(3), 363-366 (1998).

10. Shahid MJ, Ahmad F, Asif M, Sultan MN. Visual outcome in diabetic macular edema after grid laser treatment. Professional Med J 2016;23(4):478-483.

11. Shimura M, Yasuda K, Nakazawa T et al. Effective Treatment of Diffuse Diabetic Macular Edema by Temporal Grid Pattern Photocoagulation.Ophthalmic Surg Lasers Imaging 2004; 35:270-280.

12. Ingrid U. Scott, Ronald P. Danis, Susan B. Bressler. Effect of Focal/Grid photocoagulation on Visual acuity and Retinal thickening in Eyes with Noncenter Involved Clinically Significant Macular Edema. Retina. 2009 May ; 29(5):

613-617. 